University of Nebraska - Lincoln

DigitalCommons@University of Nebraska - Lincoln

2011

\title{
Comparison of CERES surface radiation fluxes with surface observations over Loess Plateau
}

\author{
Hongru Yan \\ Lanzhou University \\ Jianping Huang \\ Lanzhou University, hjp@lzu.edu.cn \\ Patrick Minnis \\ NASA Langley Research Center \\ Tianhe Wang \\ Lanzhou University \\ Jianrong $\mathrm{Bi}$ \\ Lanzhou University
}

Follow this and additional works at: https://digitalcommons.unl.edu/nasapub

Part of the Physical Sciences and Mathematics Commons

Yan, Hongru; Huang, Jianping; Minnis, Patrick; Wang, Tianhe; and Bi, Jianrong, "Comparison of CERES surface radiation fluxes with surface observations over Loess Plateau" (2011). NASA Publications. 101. https://digitalcommons.unl.edu/nasapub/101

This Article is brought to you for free and open access by the National Aeronautics and Space Administration at DigitalCommons@University of Nebraska - Lincoln. It has been accepted for inclusion in NASA Publications by an authorized administrator of DigitalCommons@University of Nebraska - Lincoln. 


\title{
Comparison of CERES surface radiation fluxes with surface observations over Loess Plateau
}

\author{
Hongru Yan ${ }^{\text {a }}$, Jianping Huang ${ }^{\mathrm{a}, *}$, Patrick Minnis ${ }^{\mathrm{b}}$, Tianhe Wang ${ }^{\mathrm{a}}$, Jianrong $\mathrm{Bi}^{\mathrm{a}}$ \\ a Key Laboratory for Semi-Arid Climate Change of the Ministry of Education, College of Atmospheric Sciences, Lanzhou University, Lanzhou 730000, China \\ ${ }^{\mathrm{b}}$ NASA Langley Research Center, Hampton, VA 23666, USA
}

\section{A R T I C L E I N F O}

Article history:

Received 19 August 2010

Received in revised form 8 February 2011

Accepted 8 February 2011

Available online 12 March 2011

\section{Keywords:}

surface radiative fluxes

CERES/SSF

validation

\begin{abstract}
A B S T R A C T
Surface energy budget is an important factor in weather and climate processes. To estimate the errors in satellite-retrieved surface radiation budget over the interior of China, instantaneous-footprint surface radiation fluxes from the Terra/Aqua FLASHFlux SSF product are compared with the measurements taken at the Semi-Arid Climate and Environment Observatory of Lanzhou University (SACOL) from July 2008 to March 2010. Validation is performed separately for different conditions: clear-sky and cloudy-sky, daytime and nighttime for four seasons. Differences between the FLASHFlux CERES shortwave radiation flux and surface measurements have larger standard deviations in cloudy-sky conditions than in clear-sky conditions, indicating that cloud contamination increases uncertainty in the retrieval algorithm. Upward shortwave radiation flux (USW) is overestimated in cloudy conditions suggesting that the cloud parameters and surface scene type in the retrieval process are not optimal for northwestern China. The CERES downward longwave radiation fluxes (DLW) accurately follow the variation of surface measurements during daytime, but are slightly underestimated during nighttime due to the coarse sounding profile and undetected low clouds at nighttime. The CERES upwelling longwave radiation fluxes (ULW) are strongly underestimated during daytime but are slightly underestimated during nighttime regardless of cloud coverage. This large bias could be caused by an underestimate of surface skin temperature and/or surface emissivity, or spatial inhomogeneity around the site. Generally, except for diurnal ULW, other components of the surface radiative fluxes obtained from CERES SSF datasets are close to meeting the accuracy requirements for climate research.

(C) 2011 Elsevier Inc. All rights reserved.
\end{abstract}

\section{Introduction}

The surface radiation budget is a fundamental component of the atmospheric and surface energy budgets, which are important factors in climate change. In order to better monitor weather and climate changes, measurements of surface radiation (Hartmann et al., 1986; Ramanathan, 1987; Ramanathan et al., 1989) are needed globally, not just over the small areas represented by surface radiometer measurements. Hence, satellite-derived surface radiation flux is used to complement ground-based measurements. To accurately monitor the surface radiation budget and estimate surface radiative forcing on a global scale, it is necessary to determine the uncertainties in the satellite-derived fluxes by comparing them with surface-based measurements of the same quantity.

The objective of the National Aeronautics and Space Administration (NASA) Clouds and the Earth's Radiant Energy System (CERES) project is to investigate the critical role that clouds and aerosols play in modulating the radiative energy flow within the Earth-atmosphere

\footnotetext{
* Corresponding author.

E-mail address: hjp@lzu.edu.cn (J. Huang).
}

system (Wielicki et al., 1998). The CERES broadband scanning radiometers (shortwave: $0.2-5 \mu \mathrm{m}$, total: $0.2-100.0 \mu \mathrm{m}$ ), an improved version of the Earth Radiation Budget Experiment (ERBE) radiometers (Kopia, 1986), were designed to be twice as accurate as the ERBE scanning radiometer. Furthermore, the CERES project provides not only radiation fluxes at the top of the atmosphere (TOA) as ERBE did, but also radiation fluxes at the surface and at several levels within the atmosphere (Barkstrom, 1990; Wielicki et al., 1996). Four different models are incorporated into the CERES processing to provide independent estimates of surface fluxes.

Comparisons between ground- and satellite-based observations need to be conducted carefully because of significant spatial and temporal differences between two different observing platforms. Complete validation of CERES surface radiative fluxes with independent ground-truth observations should account for many variables, such as surface type, time of day, viewing and illumination angles, etc. The Baseline Surface Radiation Network (BSRN) project (Ohmura et al., 1998), including 43 stations all over the world, was developed to detect important changes in the radiation field at the Earth's surface and to calibrate satellite-based estimates of the surface radiative fluxes. Kratz et al. (2010) used a number of the BSRN sites with others to validate one of the CERES surface radiation models. That study covered many areas 
Table 1

Surface-measured radiative fluxes and their uncertainties.

\begin{tabular}{lllll}
\hline $\begin{array}{l}\text { Radiation } \\
\text { properties }\end{array}$ & $\begin{array}{l}\text { Uncertainty } \\
(\%)\end{array}$ & $\begin{array}{l}\text { Sampling } \\
\text { interval (s) }\end{array}$ & Instrument & Period \\
\hline $\begin{array}{c}\text { Downward } \\
\text { shortwave flux }\end{array}$ & 2 & 1 & $\begin{array}{l}\text { CM21, Kipp and } \\
\text { Zonen }\end{array}$ & 2008.07-2010.03 \\
$\begin{array}{c}\text { Up shortwave } \\
\text { flux }\end{array}$ & 2 & 1 & $\begin{array}{l}\text { CM21, Kipp and } \\
\text { Zonen } \\
\text { CG4, Kipp and }\end{array}$ & 2008.07-2010.03 \\
$\begin{array}{c}\text { Downward } \\
\text { longwave flux }\end{array}$ & 3 & 1 & $\begin{array}{l}\text { Zonen } \\
\text { CG4, Kipp and }\end{array}$ & 2008.07-2010.03 \\
$\begin{array}{c}\text { Up longwave } \\
\text { flux }\end{array}$ & 3 & 1 & Zonen & \\
\hline
\end{tabular}

but not the interior of Asia. Indeed, there are no BSRN or other sites distributed in the interior of the Asian continent, where a special type of semi-arid land surface exists that often serves as a dust aerosol source. Fu et al. (2006) showed that semi-arid lands, especially those located in mid-latitude inner continental regions, are some of the most sensitive areas to climate change. The Semi-Arid Climate and Environment Observatory of Lanzhou University (SACOL) located at $35^{\circ} 56^{\prime} \mathrm{N}, 104^{\circ} 08^{\prime}$ $\mathrm{E}$, the only international long term climate observation site over the Loess Plateau of China, was established in 2005 and has been focusing on filling gaps in the validation of space-borne observations over this special area (Huang et al., 2008).

This paper presents comparisons of the four components of the surface radiation field with matching ground-based observations from July 2008 to March 2010 at SACOL. The present study is limited to the validation of clear-sky and cloudy-sky fluxes, part of the singlescanner footprint (SSF) product, determined from the CERES instruments on board the Terra and Aqua satellites. A brief description of the standard surface measurements and satellite-retrieval algorithms is presented in Section 2. Validation of all components of the satellitederived surface radiation budget and analysis of possible causes for the biases are presented in Section 3, while Section 4 presents the summary and conclusions.

\section{Data and methodology}

\subsection{Surface data}

Ground-measured surface radiation flux data have been used to provide the ground-truth for development of the technique and for validating the satellite-estimated surface radiation flux values. Before surface-measured data can serve as a baseline to validate satellite
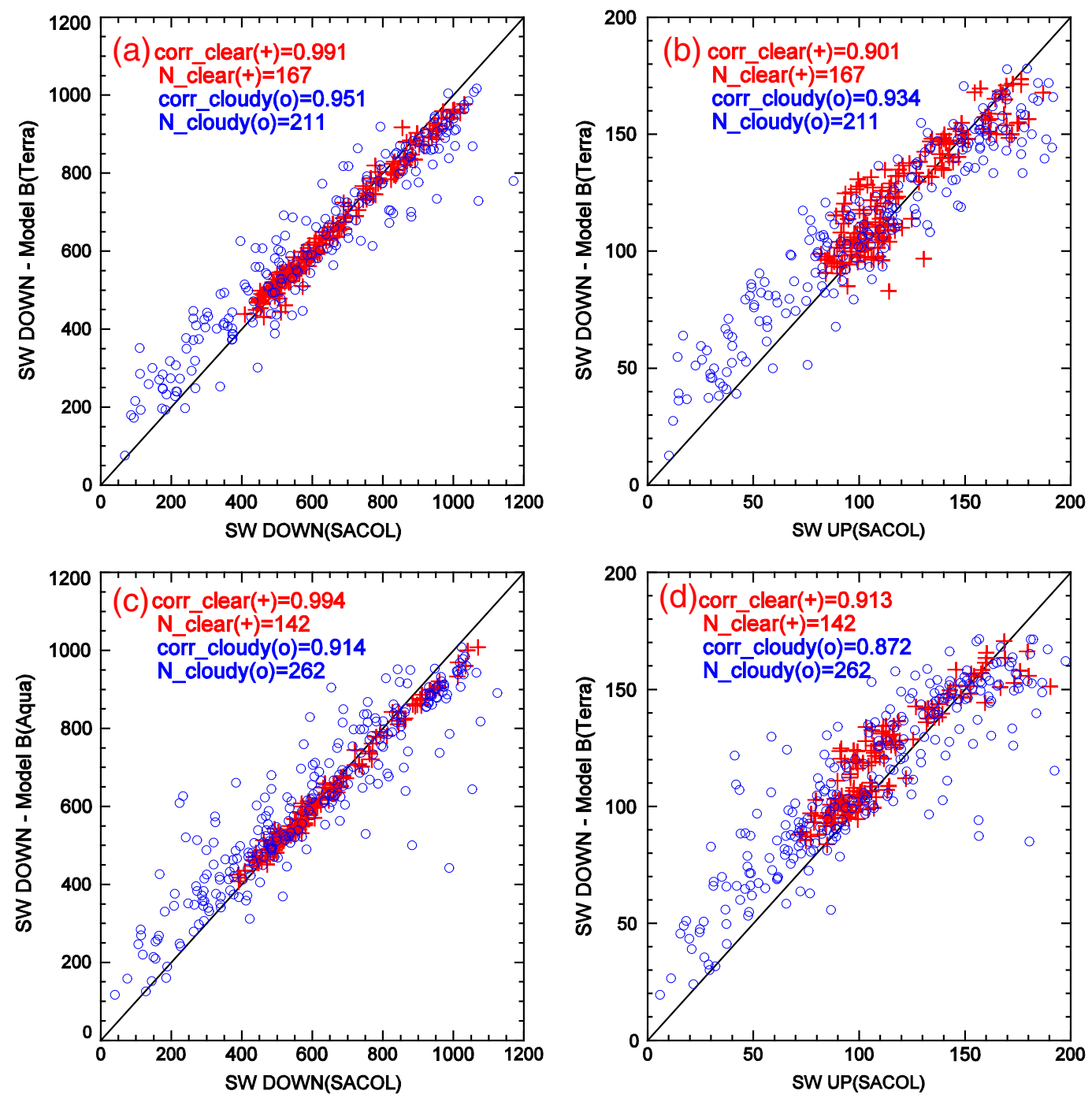

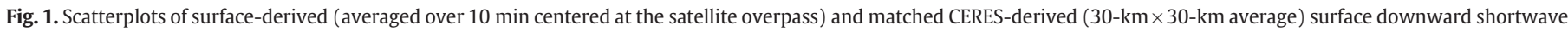

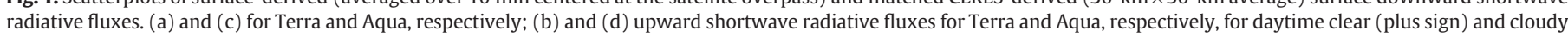
(circle) over the SACOL. 
Table 2

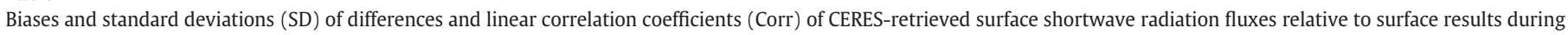
daytime. The abbreviations DSW and USW represent downward and upward shortwave radiation fluxes, respectively.

\begin{tabular}{|c|c|c|c|c|c|c|c|c|c|c|}
\hline & & \multirow[t]{2}{*}{ No. } & \multicolumn{4}{|c|}{ DSW (CERES)-DSW (sfc) } & \multicolumn{4}{|c|}{ USW (CERES)-USW (sfc) } \\
\hline & & & $\begin{array}{l}\text { Bias } \\
\left(\mathrm{Wm}^{-2}\right)\end{array}$ & $\begin{array}{l}\mathrm{SD} \\
\left(\mathrm{Wm}^{-2}\right)\end{array}$ & $\begin{array}{l}\text { SD } \\
(\%)\end{array}$ & corr & $\begin{array}{l}\text { Bias } \\
\left(\mathrm{Wm}^{-2}\right)\end{array}$ & $\begin{array}{l}\mathrm{SD} \\
\left(\mathrm{Wm}^{-2}\right)\end{array}$ & $\begin{array}{l}\text { SD } \\
(\%)\end{array}$ & corr \\
\hline \multirow[t]{4}{*}{ Spring } & Terra (clear) & 29 & -7.5 & 25.4 & 3.0 & 0.95 & 1.7 & 5.8 & 3.9 & 0.90 \\
\hline & Terra (cloudy) & 49 & 2.9 & 92.5 & 25.8 & 0.94 & 6.1 & 15.8 & 31.9 & 0.95 \\
\hline & Aqua (clear) & 19 & -22.2 & 20.9 & 2.4 & 0.98 & 1.2 & 6.9 & 4.5 & 0.84 \\
\hline & Aqua (cloudy) & 62 & 40.6 & 109.8 & 35.1 & 0.91 & 13.5 & 20.6 & 43.0 & 0.90 \\
\hline \multirow[t]{4}{*}{ Summer } & Terra (clear) & 21 & -41.6 & 13.8 & 1.4 & 0.96 & -7.8 & 11.8 & 7.3 & 0.73 \\
\hline & Terra (cloudy) & 59 & -20.3 & 104.3 & 28.7 & 0.95 & -7.2 & 22.1 & 45.1 & 0.94 \\
\hline & Aqua (clear) & 10 & -51.7 & 15.5 & 1.4 & 0.98 & -10.4 & 15.5 & 8.7 & 0.71 \\
\hline & Aqua (cloudy) & 69 & -36.5 & 131.5 & 31.9 & 0.87 & -6.5 & 25.4 & 34.3 & 0.84 \\
\hline \multirow[t]{4}{*}{ Autumn } & Terra (clear) & 40 & -11.3 & 21.8 & 3.5 & 0.98 & -1.0 & 7.9 & 7.2 & 0.82 \\
\hline & Terra (cloudy) & 58 & 16.3 & 85.3 & 38.2 & 0.93 & 4.5 & 16.5 & 49.8 & 0.91 \\
\hline & Aqua (clear) & 36 & -8.5 & 19.8 & 3.5 & 0.99 & 3.4 & 6.2 & 6.5 & 0.88 \\
\hline & Aqua (cloudy) & 71 & 19.8 & 94.9 & 41.4 & 0.93 & 7.1 & 17.8 & 51.5 & 0.89 \\
\hline \multirow[t]{4}{*}{ Winter } & Terra (clear) & 77 & 6.2 & 21.9 & 4.2 & 0.95 & 9.6 & 11.2 & 10.9 & 0.66 \\
\hline & Terra (cloudy) & 54 & 31.9 & 71.0 & 25.2 & 0.91 & 13.8 & 14.7 & 32.4 & 0.89 \\
\hline & Aqua (clear) & 77 & 3.3 & 19.3 & 3.7 & 0.97 & 14.1 & 7.9 & 8.4 & 0.86 \\
\hline & Aqua (cloudy) & 60 & 42.7 & 61.7 & 18.9 & 0.90 & 15.9 & 18.4 & 28.1 & 0.80 \\
\hline \multirow[t]{4}{*}{ Whole } & Terra (clear) & 167 & -6.4 & 26.4 & 4.1 & 0.99 & 3.5 & 11.5 & 10.3 & 0.90 \\
\hline & Terra (cloudy) & 211 & 6.3 & 91.4 & 30.4 & 0.95 & 3.6 & 19.2 & 41.8 & 0.93 \\
\hline & Aqua (clear) & 142 & -7.0 & 24.5 & 3.8 & 0.99 & 7.9 & 11.0 & 10.1 & 0.91 \\
\hline & Aqua (cloudy) & 261 & 15.1 & 107.8 & 33.7 & 0.91 & 7.1 & 22.5 & 41.6 & 0.87 \\
\hline
\end{tabular}

retrievals, surface observations need to be made and the accuracies need to be guaranteed. Most of the SACOL instruments (Huang et al., 2008) are the same as those used for the Baseline Surface Radiation Network (BSRN), Coordinated Energy and water cycle Observations Project (CEOP), AErosol RObotic NETwork (AERONET) and MicroPulse Lidar NETwork (MPLNET). The quality of data measured at SACOL can be guaranteed by using precision instruments with daily maintenance and quality control. Table 1 lists characteristics, such as the uncertainties and available period, of the SACOL radiative flux observations. The high-precision surface radiation monitoring system consists of up-facing and down-looking pyranometers (CM21, Kipp and Zonen; 0.3-3.0 $\mu \mathrm{m}$ ) for measuring the downwelling shortwave (DSW) and upwelling shortwave radiation (USW) fluxes, respectively, and of their longwave counterparts, pyrgeometers (CG4, Kipp and Zonen; 4.5-42.0 $\mu \mathrm{m}$ ), for measuring downwelling longwave (DLW) and upwelling radiation (ULW). The CM21 and CG4 radiometers are configured on a mounting plate installed on one standard ' $\mathrm{H}$ ' shape horizontal platform (approximately $1.5 \mathrm{~m}$ height above the surface) where the field of view is unobstructed in all directions. All radiation parameters are sampled each second but taken at a 1-minute time resolution. The quality of each dataset was checked by utilizing the BSRN quality control procedure (Ohmura et al., 1998). Furthermore, a set of redundant broadband pyranometers, such as the Normal Incidence Pyrheliometer (NIP) and Black and White radiometer (B\&W), are used to monitor the data quality every day. In addition to the inter-comparison with other instruments, the radiometers are compared with the reference instruments of China Meteorological Administration annually to obtain the calibration parameters of radiometers. In order to ensure the quality of the surface observations and consistency between the satellite and ground-based observations, data recorded on days having rain and snow measurements were not used in this analysis.

\subsection{Satellite data}

The CERES-based radiative fluxes that are compared here with the surface observations are archived in the Terra Version2E 2 F and Aqua Version2E 2 F of the Fast Longwave and Shortwave Radiative Flux (FLASHFlux) datasets (Stackhouse et al., 2006). The differences between the Versions 2E and 2 F TOA SW fluxes are only $0.01 \%$ due to a correction applied in Version $2 \mathrm{~F}$ to account for erroneous values of the spectral correction coefficients. Thus, these two datasets can be analyzed together in this study. Both versions of FLASHFlux used data collected by the CERES project (Caldwell et al., 2008) and the CERES Edition 2 algorithms. The FLASHFlux project was envisioned as a conduit whereby CERES data could be provided to the community within a week of the initial measurements, with the trade-off that some degree of accuracy would be exacted to gain turnaround time. FLASHFlux SSF datasets combine CERES broadband radiation flux measured 20-km resolution, Moderate Resolution Imaging Spectroradiometer (MODIS) cloud (Minnis et al., 2008b, 2011) and aerosol properties retrieved at a 1-km resolution, and ancillary meteorology fields to form a comprehensive, high-quality compilation of satellitederived cloud, aerosol, and radiation budget information for radiation and climate studies.

CERES uses two separate approaches for estimating shortwave fluxes at the surface. One method is the Li et al. (1993) algorithm (SW model A) based on radiative transfer modeling that uses the TOA reflected shortwave flux and precipitable water to derive the net shortwave flux at the surface. And then downward and upward fluxes are derived by using surface albedos (Li \& Garand, 1994). However, this method is only available for clear conditions. A second method, the NASA Langley Parameterized Shortwave Algorithm (LPSA) method (SW model B) described by Gupta et al. (2001), is also used to compute the downward shortwave fluxes at the surface as well as the net fluxes under all-sky conditions. The upwelling shortwave fluxes are derived as the product of surface albedo and DSW.

There are also two separate techniques to estimate surface LW fluxes. For the clear sky case, the surface LW fluxes are computed by the method of Inamdar and Ramanathan (1997) (LW model A) using the CERES broadband and 8-12 $\mu \mathrm{m}$ window radiance measurements, surface temperature, temperature profile, precipitable water and the surface emissivity maps developed by Wilber et al. (1999). For all-sky conditions, a second technique, the NASA Langley Parameterized Longwave Algorithm (LPLA) method (LW model B) described by Gupta et al. (1992) is used to compute DLW, ULW, and net surface LW using a set of parameterizations.

The FLASHFlux SSF product is processed very shortly after the data acquisition date, and therefore, some data gaps occur when some of the data are delayed. The FLASHFlux project focuses on the Model B parameters that provide surface fluxes for both cloudy and clear-sky 

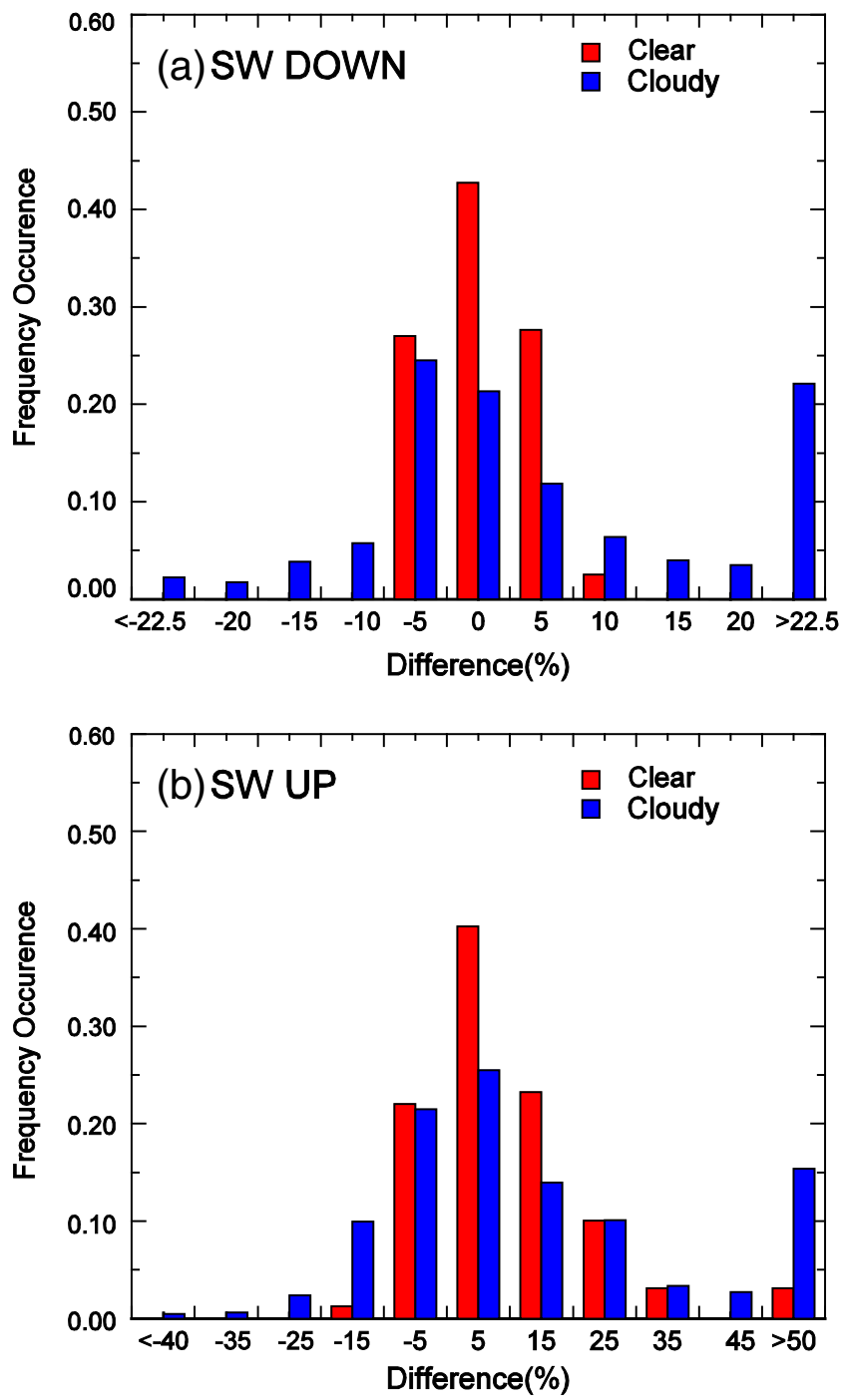

Fig. 2. Histograms of surface SW flux differences between CERES and ground-based observations from the data presented in Fig. 1. The first and last X-axis labels are the range for the corresponding bar, and others are the center of range for each bar.

conditions. Owing to lack of sufficient samples for the results calculated with Model A, validation of satellite-derived instantaneous surface fluxes in this paper is limited only to those parameters calculated by LPSA and LPLA.

To facilitate interpretation of the results, the comparisons are divided into clear-sky and cloudy condition using the CERES cloud fraction as the criterion. For clear-sky conditions, cloud fraction cannot exceed $5 \%$, while cloudy conditions have cloud fractions greater than $5 \%$. The satellitederived cloud properties were averaged in a $30-\mathrm{km} \times 30-\mathrm{km}$ box centered on the SACOL, and the surface measured radiation properties were averaged over 10-minute intervals centered at the time of each satellite overpass.

\section{Satellite algorithms}

\subsection{LPSA}

The SW-model B (LPSA; Gupta et al., 2001) consists of physical parameterizations that account for the attenuation of solar radiation in simple terms separately for clear and cloudy atmospheres. Surface incoming solar radiation flux, $F_{s d}$, is computed as:

$F_{\text {sd }}=F_{\text {toa }} T_{a} T_{c}$, where $F_{\text {toa }}$ is the corresponding TOA insolation, which is available in the CERES processing system, $T_{a}$ is the transmittance of the clear atmosphere, and $T_{C}$ is the cloud transmittance (Darnell et al., 1988, 1992).

Net or absorbed SW radiation, $F_{S N}$, is computed as

$F_{S N}=F_{S D}\left(1-A_{S}\right)$

where $A_{S}$ is surface albedo, which also affects the downward SW radiation through the backscattered radiation. The all-sky surface albedo is computed as:

$A_{S}=A_{\text {Sovc }}+\left(A_{\text {Sclr }}-A_{\text {Sovc }}\right) T_{C}^{2}$

where $A_{\text {Sclr }}$ and $A_{\text {Sovc }}$ represent surface albedos for clear-sky and overcast conditions respectively. $A_{S c l r}$ and $A_{\text {sovc }}$ may be substantially different because of differences between illumination geometry under clear-sky and overcast conditions. Staylor and Wilber (1990) obtained $A_{\text {sclr }}$ and $A_{\text {Sovc }}$ from different sources for different surface types. For a detailed description of LPSA, the reader is referred to Gupta et al. (2001).

Generally speaking, the NASA LPSA method uses precipitable water, ozone, humidity profiles, solar zenith angle, broad band (BB) TOA clear-sky and cloud SW albedo, cloud fraction, and ERBE scene type as the inputs, which might introduce errors into the retrievals.

\section{2. $L P L A$}

The LW-model B (LPLA; described in Gupta et al., 1992) is a fast parameterization developed from an accurate narrowband radiative transfer model (Gupta, 1989) in which all-sky DLW is computed as:

$F_{L D}=C_{1}+C_{2} A_{c}$

where $A_{c}$ represents the fractional cloud cover, $C_{1}$ is clear-sky downward longwave flux, which is computed in terms of an "effective emitting temperature" of the atmosphere and the column water vapor. $C_{2}$ is cloud radiative effect for overcast condition, which is expressed as:

$C_{2}=\frac{T_{c b}^{4}}{\left(B_{0}+B_{1} W_{c}+B_{2} W_{c}^{2}+B_{3} W_{c}^{3}\right)}$,

where $T_{c b}$ represents the cloud-base temperature for each footprint, $W_{c}$ is the water vapor burden below the cloud base, and $B_{0}, B_{1}, B_{2}$, and $B_{3}$ are regression coefficients. The effective emitting temperature and column water vapor are computed from the temperature and humidity profiles available from the Meteorology, Ozone, and Aerosol (MOA) Meteorological Database maintained for all CERES processing (Gupta et al., 1997). Presently, MOA profiles are based on Global Modeling and Assimilation Office (GMAO) GEOS-5 products. Fractional cloud amount and cloud-base height are available at the time of flux computation from the cloud subsystem of CERES processing (Minnis et al., 2008b, 2011) where they are derived using high-resolution imager data from MODIS, which is also part of the Terra and Aqua instrument complements.

The ULW flux, $F_{U L}$, computed directly from the surface temperature (Gupta, 1989), is expressed as:

$F_{U L}=\varepsilon_{S} \sigma T_{S}^{4}$

where $\sigma$ is the Stefan-Boltzman constant, $T_{s}$ represents the surface skin temperature, and $\varepsilon_{s}$ is the surface emissivity. For the SACOL area, a value of $\varepsilon_{s}=0.99$ was used based on the maps of Wilber et al. (1999). 
Table 3a

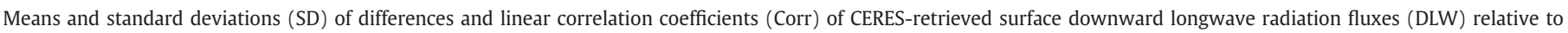
surface results during daytime and nighttime.

\begin{tabular}{|c|c|c|c|c|c|c|c|c|c|c|c|}
\hline & & \multicolumn{10}{|c|}{ DLW (CERES)-DLW (sfc) } \\
\hline & & \multicolumn{5}{|l|}{ Day } & \multicolumn{5}{|c|}{ Night } \\
\hline & & No. & $\begin{array}{l}\text { Bias } \\
\left(\mathrm{Wm}^{-2}\right)\end{array}$ & $\begin{array}{l}\text { SD } \\
\left(\mathrm{Wm}^{-2}\right)\end{array}$ & $\begin{array}{l}\text { SD } \\
(\%)\end{array}$ & corr & No. & $\begin{array}{l}\text { Bias } \\
\left(\mathrm{Wm}^{-2}\right)\end{array}$ & $\begin{array}{l}\mathrm{SD} \\
\left(\mathrm{Wm}^{-2}\right)\end{array}$ & $\begin{array}{l}\text { SD } \\
(\%)\end{array}$ & corr \\
\hline \multirow[t]{4}{*}{ Spring } & Terra (clear) & 29 & -8.3 & 9.2 & 3.5 & 0.91 & 19 & -24.7 & 8.0 & 3.3 & 0.95 \\
\hline & Terra (cloudy) & 49 & 1.0 & 16.7 & 5.9 & 0.91 & 65 & -17.7 & 15.4 & 5.4 & 0.92 \\
\hline & Aqua (clear) & 19 & -15.6 & 11.6 & 4.3 & 0.85 & 25 & -24.3 & 14.2 & 5.3 & 0.88 \\
\hline & Aqua (cloudy) & 62 & 3.1 & 16.7 & 6.1 & 0.90 & 63 & -15.6 & 16.8 & 6.0 & 0.88 \\
\hline \multirow[t]{4}{*}{ Summer } & Terra (clear) & 21 & -8.3 & 9.5 & 2.9 & 0.82 & 24 & -19.7 & 9.6 & 3.2 & 0.89 \\
\hline & Terra (cloudy) & 59 & -1.0 & 12.2 & 3.5 & 0.94 & 57 & -11.1 & 17.5 & 4.8 & 0.84 \\
\hline & Aqua (clear) & 10 & -15.2 & 10.5 & 3.5 & 0.90 & 18 & -17.2 & 7.7 & 2.6 & 0.89 \\
\hline & Aqua (cloudy) & 69 & 1.3 & 16.4 & 4.7 & 0.91 & 53 & -13.9 & 18.3 & 5.5 & 0.75 \\
\hline \multirow[t]{4}{*}{ Autumn } & Terra (clear) & 40 & -0.4 & 10.3 & 4.4 & 0.95 & 42 & -12.1 & 8.2 & 3.3 & 0.96 \\
\hline & Terra (cloudy) & 58 & 4.2 & 15.4 & 5.6 & 0.91 & 58 & -16.8 & 19.2 & 6.5 & 0.89 \\
\hline & Aqua (clear) & 36 & -0.5 & 10.9 & 4.5 & 0.94 & 54 & -17.3 & 15.4 & 5.5 & 0.87 \\
\hline & Aqua (cloudy) & 71 & 6.8 & 15.8 & 5.5 & 0.92 & 55 & -20.8 & 22.0 & 7.6 & 0.82 \\
\hline \multirow[t]{4}{*}{ Winter } & Terra (clear) & 77 & 4.5 & 6.7 & 3.6 & 0.91 & 67 & -10.4 & 8.2 & 3.8 & 0.86 \\
\hline & Terra (cloudy) & 45 & 11.0 & 15.3 & 6.9 & 0.90 & 60 & -11.9 & 15.9 & 6.4 & 0.80 \\
\hline & Aqua (clear) & 77 & 9.4 & 8.0 & 4.1 & 0.87 & 75 & -11.2 & 9.5 & 4.6 & 0.80 \\
\hline & Aqua (cloudy) & 60 & 17.9 & 16.2 & 7.0 & 0.86 & 69 & -8.1 & 16.8 & 7.0 & 0.80 \\
\hline \multirow[t]{4}{*}{ Whole } & Terra (clear) & 167 & -0.5 & 10.0 & 4.3 & 0.98 & 152 & -14.1 & 9.8 & 3.8 & 0.98 \\
\hline & Terra (cloudy) & 211 & 3.5 & 15.4 & 5.8 & 0.96 & 240 & -14.5 & 17.1 & 5.9 & 0.94 \\
\hline & Aqua (clear) & 142 & 1.8 & 13.5 & 5.8 & 0.96 & 172 & -15.6 & 12.9 & 5.0 & 0.95 \\
\hline & Aqua (cloudy) & 262 & 7.0 & 17.3 & 6.5 & 0.95 & 240 & -14.3 & 18.9 & 6.7 & 0.92 \\
\hline
\end{tabular}

\section{Results and discussion}

There is good agreement between surface and CERES SW radiation fluxes, especially in clear-sky conditions. The phenomenon that relatively smaller correlation coefficient and larger standard deviation of satellite shortwave radiation flux in cloudy condition than that in clear-sky indicates cloud contamination. The DLW retrieved from LPLA accurately follows the variation of surface measurements at SACOL during daytime, but is slightly underestimated during night. CERES ULW is remarkably underestimated probably because of the errors from the input in the processing.

\subsection{Surface shortwave radiative flux}

Fig. 1a and c show comparisons between surface-derived and matched Terra and Aqua CERES-derived DSW fluxes for clear (red points) and cloudy (blue points) over the SACOL during daytime from July 2008 to March 2010. The biases, standard deviations (SD) of the differences, and linear correlation coefficients of the Terra and Aqua CERES retrievals relative to the surface results are summarized in Table 2, which is divided into four seasons along with the annual mean results. Both of the Terra and Aqua CERES-derived DSW fluxes for clear skies are in good accordance with the surface-derived DSW as indicated

Table 3b

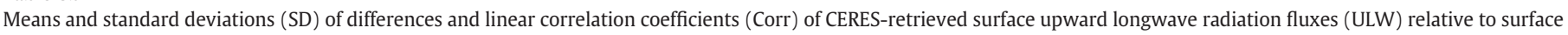
results during daytime and nighttime.

\begin{tabular}{|c|c|c|c|c|c|c|c|c|c|c|c|}
\hline & & \multicolumn{10}{|c|}{ ULW (CERES)-ULW (sfc) } \\
\hline & & \multicolumn{5}{|l|}{ Day } & \multicolumn{5}{|c|}{ Night } \\
\hline & & No. & $\begin{array}{l}\text { Bias } \\
\left(\mathrm{Wm}^{-2}\right)\end{array}$ & $\begin{array}{l}\mathrm{SD} \\
\left(\mathrm{Wm}^{-2}\right)\end{array}$ & $\begin{array}{l}\text { SD } \\
(\%)\end{array}$ & corr & No. & $\begin{array}{l}\text { Bias } \\
\left(\mathrm{Wm}^{-2}\right)\end{array}$ & $\begin{array}{l}\mathrm{SD} \\
\left(\mathrm{Wm}^{-2}\right)\end{array}$ & $\begin{array}{l}\text { SD } \\
(\%)\end{array}$ & corr \\
\hline \multirow[t]{4}{*}{ Spring } & Terra (clear) & 29 & -102.9 & 17.5 & 2.7 & 0.90 & 19 & -19.8 & 7.7 & 2.3 & 0.96 \\
\hline & Terra (cloudy) & 49 & -76.9 & 43.8 & 7.8 & 0.83 & 65 & -14.1 & 11.2 & 3.3 & 0.93 \\
\hline & Aqua (clear) & 19 & -82.9 & 15.0 & 2.3 & 0.90 & 25 & -10.1 & 13.4 & 4.3 & 0.87 \\
\hline & Aqua (cloudy) & 62 & -47.6 & 41.5 & 8.4 & 0.81 & 63 & -14.9 & 10.5 & 3.2 & 0.92 \\
\hline \multirow[t]{4}{*}{ Summer } & Terra (clear) & 21 & -86.1 & 35.7 & 5.3 & 0.75 & 24 & -13.7 & 8.8 & 2.2 & 0.87 \\
\hline & Terra (cloudy) & 59 & -89.1 & 53.8 & 8.9 & 0.57 & 57 & -10.2 & 11.5 & 2.9 & 0.75 \\
\hline & Aqua (clear) & 10 & -85.9 & 52.7 & 7.9 & 0.18 & 18 & -11.7 & 9.1 & 2.4 & 0.74 \\
\hline & Aqua (cloudy) & 69 & -61.2 & 53.0 & 8.9 & 0.50 & 53 & -14.9 & 12.6 & 3.2 & 0.68 \\
\hline \multirow[t]{4}{*}{ Autumn } & Terra (clear) & 40 & -59.5 & 16.4 & 3.5 & 0.91 & 42 & -7.0 & 9.7 & 2.9 & 0.95 \\
\hline & Terra (cloudy) & 58 & -43.4 & 26.6 & 6.0 & 0.81 & 58 & -12.2 & 10.9 & 3.3 & 0.95 \\
\hline & Aqua (clear) & 36 & -31.9 & 17.5 & 3.8 & 0.90 & 54 & -9.6 & 12.7 & 4.2 & 0.92 \\
\hline & Aqua (cloudy) & 71 & -23.1 & 26.8 & 6.2 & 0.84 & 55 & -13.9 & 10.8 & 3.4 & 0.93 \\
\hline \multirow[t]{4}{*}{ Winter } & Terra (clear) & 77 & -53.1 & 16.3 & 3.4 & 0.88 & 67 & -0.8 & 11.1 & 4.0 & 0.79 \\
\hline & Terra (cloudy) & 45 & -36.4 & 25.3 & 6.5 & 0.67 & 60 & -6.3 & 12.5 & 4.2 & 0.72 \\
\hline & Aqua (clear) & 77 & -34.7 & 16.2 & 3.8 & 0.78 & 75 & 2.4 & 10.0 & 3.8 & 0.81 \\
\hline & Aqua (cloudy) & 60 & -25.0 & 24.6 & 6.2 & 0.83 & 69 & -4.5 & 12.0 & 4.2 & 0.68 \\
\hline \multirow[t]{4}{*}{ Whole } & Terra (clear) & 167 & -67.4 & 27.7 & 4.4 & 0.95 & 152 & -6.9 & 12.0 & 3.8 & 0.97 \\
\hline & Terra (cloudy) & 211 & -62.5 & 45.4 & 7.9 & 0.89 & 240 & -10.7 & 11.9 & 3.5 & 0.97 \\
\hline & Aqua (clear) & 142 & -44.0 & 28.9 & 5.0 & 0.93 & 172 & -4.7 & 12.9 & 4.3 & 0.96 \\
\hline & Aqua (cloudy) & 262 & -39.4 & 41.5 & 7.8 & 0.89 & 240 & -11.7 & 12.3 & 3.7 & 0.96 \\
\hline
\end{tabular}


Table 4

Seasonal mean surface albedos from Terra, Aqua and surface observations using the ratios of USW/DSW.

\begin{tabular}{lllll}
\hline Albedo & Spring & Summer & Autumn & Winter \\
\hline Terra & 0.191 & 0.190 & 0.190 & 0.194 \\
Aqua & 0.193 & 0.193 & 0.192 & 0.195 \\
Surface & 0.188 & 0.184 & 0.169 & 0.193
\end{tabular}

by the high correlation coefficient (0.99) for the annual average. Table 2 shows that the satellite-based DSW slightly underestimates the surface results by an average of $6.4 \mathrm{~W} \mathrm{~m}^{-2}$ and $7.0 \mathrm{~W} \mathrm{~m}^{-2}$ respectively for Terra and Aqua in clear skies, while it overestimates the surface DSW by an average of $6.3 \mathrm{~W} \mathrm{~m}^{-2}$ and $15.1 \mathrm{~W} \mathrm{~m}^{-2}$ for cloudy conditions. These results suggest that, based on Eqs. (2) and (3), the averaged cloud transmittance $\left(T_{c}\right)$ and/or the all-sky surface albedo over SACOL are overestimated. Broken clouds, which can cause overestimation of $T_{c}$, are commonly found over SACOL.

In the scatter plots (Fig. 1a and c), the clear-sky DSW points are grouped tightly around the line of agreement. The SACOL clear-sky DSW fluxes exceed the satellite values at higher values of DSW and, conversely, are smaller than the CERES estimates at the low end. This is the result of seasonal differences as seen in Table 2. The satellite-retrieved DSW bias in winter is positive, which is dissimilar from those in the other three seasons. Positive clear-sky biases in winter may be due to the satellite retrieval algorithm missing large concentrations of absorbing aerosols emitted from the city heating systems during winter (Tian et al., 1997), and hence, it would overestimate clear-sky transmittance $\left(T_{a}\right)$. During the other seasons, the negative biases could be due to overestimates in the precipitable water, but that would have to be a general characteristic of the GEOS- 5 because similar results were found in comparisons over continental sites in North America and Europe by Kratz et al. (2010).

In the cloudy comparisons, the DSW bias is negative only in the spring for Terra and during summer for Aqua, and positive for all other times. The positive bias suggests that the cloud transmittance is underestimated in the simple Model-B formulation. The reason for the negative bias in spring-summer cloudy skies is not clear but may be related to more frequent occurrence of small convective clouds. At low solar zenith angles, more of the solar radiation would reflect from the sides of smaller cumulus clouds to the surface. At the low end in Fig. 1a and c, the differences are almost all positive, while the negative differences mostly occur at the upper end where the greatest amount of solar radiation
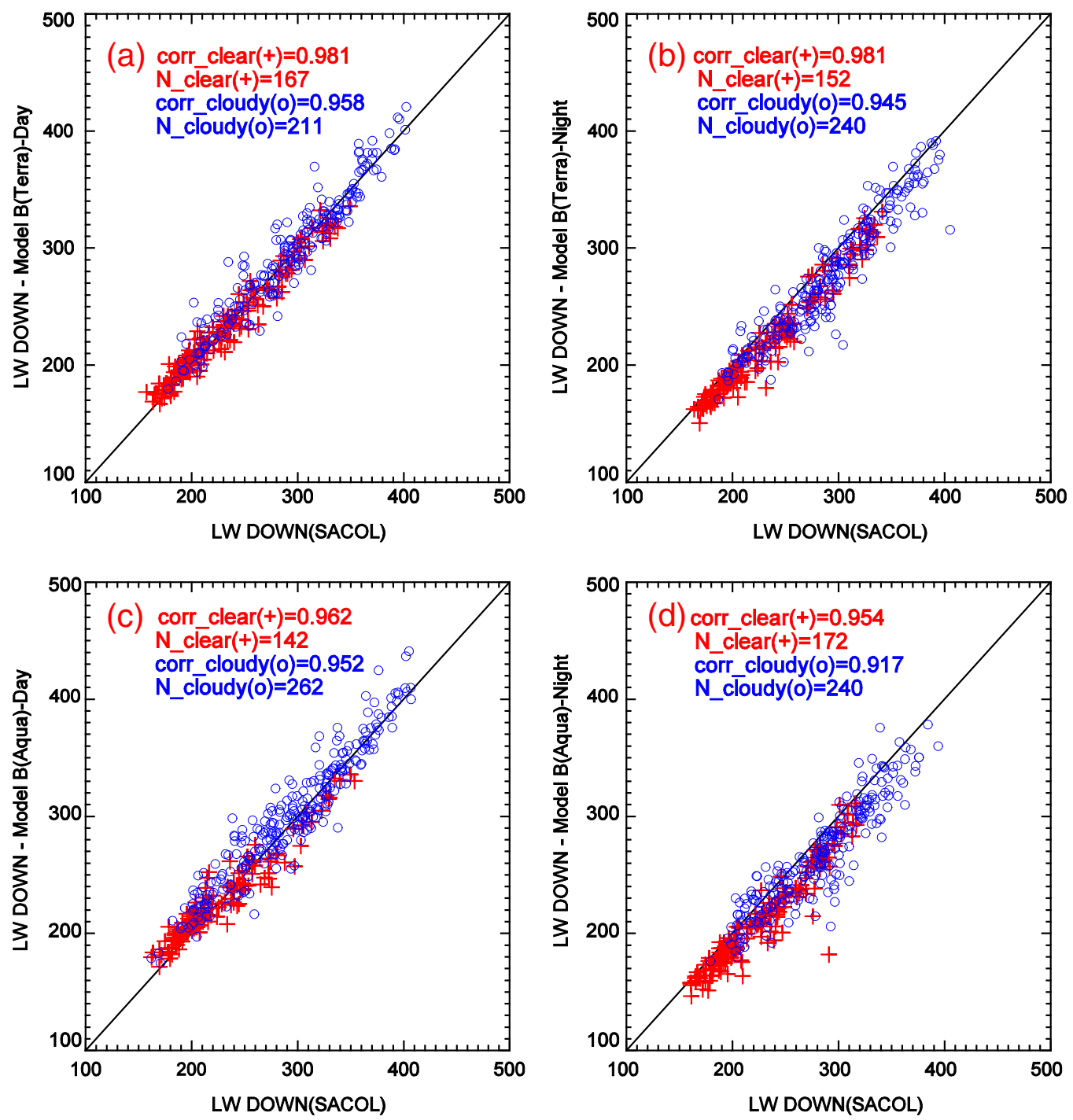

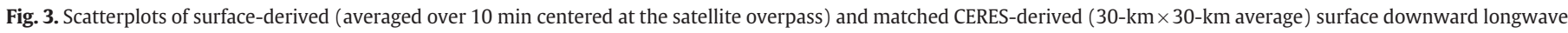

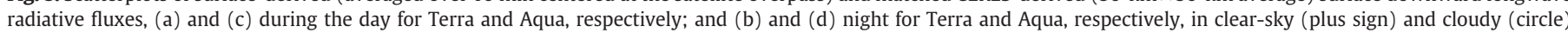
conditions over the SACOL. 

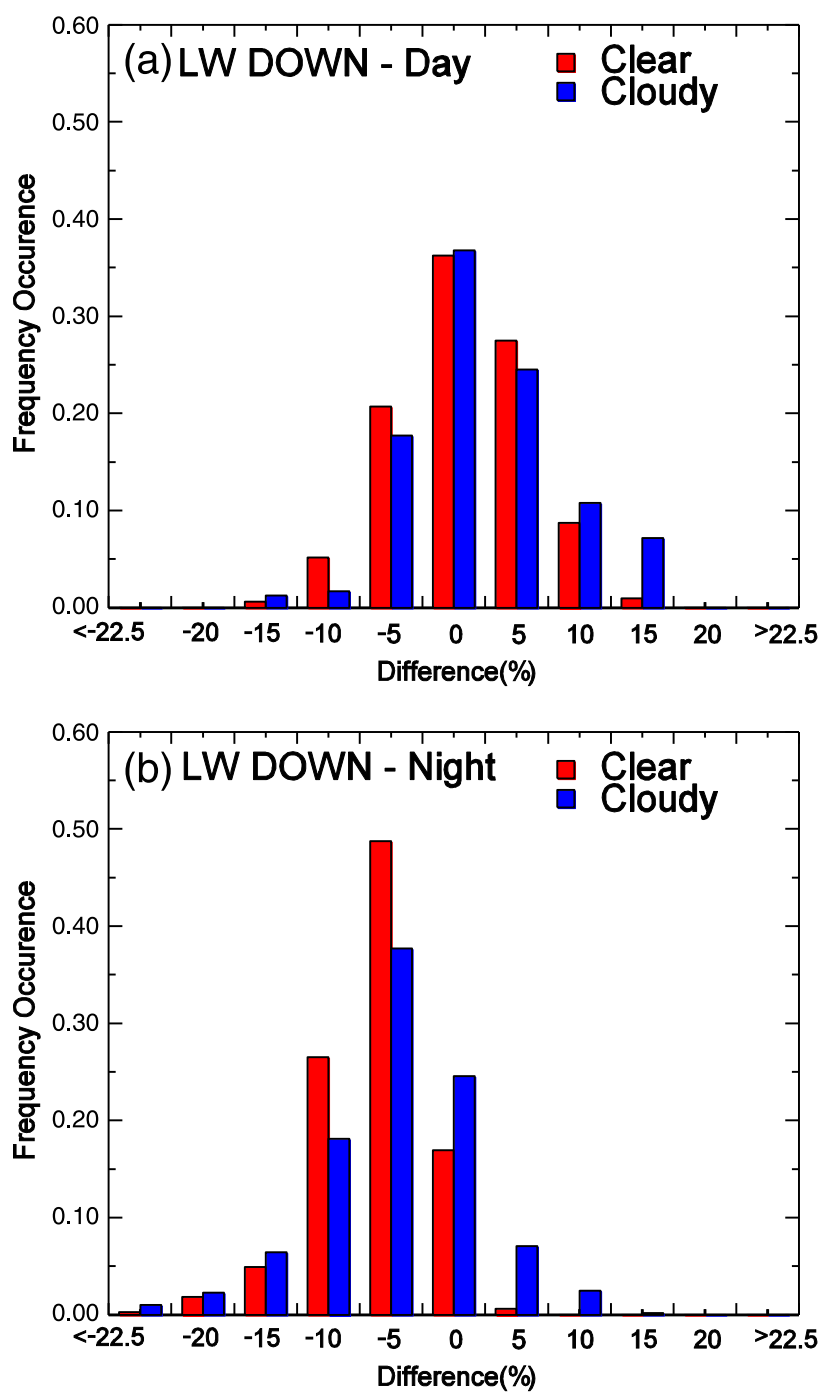

Fig. 4. Same as Fig. 2, except for the data presented in Fig. 3.

passes through the clouds. This is consistent with partly cloudy skies causing the negative biases. The scatter of points is much greater for cloudy skies than for clear conditions. This is quantified in Table 2 , which reveals that the standard deviations of the cloudy-sky differences (Terra: $91.4 \mathrm{~W} \mathrm{~m}^{-2}$; Aqua: $107.8 \mathrm{~W} \mathrm{~m}^{-2}$ ) are significantly larger than those for clear skies (Terra: $26.4 \mathrm{~W} \mathrm{~m}^{-2}$; Aqua: $24.4 \mathrm{~W} \mathrm{~m}^{-2}$ ). The clear-cloudy discrepancy is independent of season and is similar to the results found by Kratz et al. (2010) for other continental sites.

Almost all of the differences between CERES-derived and groundbased DSW fluxes are within $10 \%$ of zero in clear skies, while only about half of the differences are within $10 \%$ of zero during cloudy conditions (Fig. 2a). It is not surprising that satellite-estimated DSW is relatively unbiased in cloud-free conditions because the incoming solar radiation flux at the surface level depends primarily on the atmospheric gas and aerosol profiles, and less on cloud properties, surface albedo or satellite calibration. It was found that the standard deviations of the DSW differences rise with increasing cloud coverage from $\sim 30 \mathrm{~W} \mathrm{~m}^{-2}$ at $5 \%$ coverage to $\sim 130 \mathrm{~W} \mathrm{~m}^{-2}$ at $80 \%$ coverage, but decrease to $\sim 100 \mathrm{~W} \mathrm{~m}^{-2}$ for $100 \%$ cloud coverage. The larger SD values in cloudy conditions are most likely due to the plane-parallel assumption of horizontal and vertical homogeneity in the retrieved cloud radiative characteristics conflicting with the reality of clouds having 3-dimensional heterogeneity that is captured in the surface radiation measurements. Clouds tend more toward homogeneity in overcast conditions, especially for single-layered clouds, thus the standard deviations decrease for mostly cloudy skies. In cases where there is large spatial variability of the clouds within the CERES footprint, the surface measurements averaged over 10-minute intervals centered at the satellite overpass time may not be representative of sky conditions over the entire footprint. To examine this effect, averages of satellite DSW in the $30-\mathrm{km} \times 30-\mathrm{km}$ box were compared with 1-h surface observation averages rather than the 10minute averages. Using the longer time average drops the SD of the differences by $\sim 20 \%$ to $72.9 \mathrm{~W} \mathrm{~m}^{-2}$ for Terra and $89.6 \mathrm{~W} \mathrm{~m}^{-2}$ for Aqua in cloudy conditions (not shown). Even though the solar zenith angle and hence the surface insolation can change considerably over a 1-hour interval, they do not contribute large errors to this comparison. This is because the instantaneous satellite retrievals are always at the exact midpoint of the 60-min intervals, which is used to compute the insolation. This approximation causes uncertainties of only $2-5 \mathrm{Wm}^{-2}$ ( $1 \%$ of the mean value) relative to the hour-integrated insolation (Gupta et al., 2004).

Similar comparisons of USW for Terra and Aqua are plotted in Fig. 1b and d. Although the correlation coefficient for ground- and satellite-based USW is slightly less than that for DSW in both clear and cloudy conditions, the satellite retrievals still generally follow the variation of the surface observations. Model B overestimates USW in both clear and cloudy conditions for the whole year (Table 2). The mean USW biases for Terra and Aqua are, respectively, $3.5 \mathrm{~W} \mathrm{~m}^{-2}$ and $7.9 \mathrm{~W} \mathrm{~m}^{-2}$ in clear days and, for cloudy skies are $3.9 \mathrm{~W} \mathrm{~m}^{-2}$ and $7.1 \mathrm{~W} \mathrm{~m}^{-2}$. Since the USW is simply the product of surface albedo and DSW, the larger SDs for cloudy days (Table 2) follow those for DSW. The distribution of differences centered on 5\% (Fig. 2b), which reflect the biases, and the relatively poor correlations for clear-sky USW suggest that the surface SW albedo used in the Model B parameterization is not optimal for the SACOL site. The DSW is underestimated for clear skies and overestimated in cloudy skies, yet the USW is biased high in all conditions. This suggests that the SACOL site surface albedo is smaller than that used for Model B. The SACOL is located on the Loess Plateau, which is a hill and gully region and hence the identification and resolution of ERBE scene type might be improper. It is also notable that the sign of bias in summer is negative, which is opposite to other three seasons. The seasonal surface albedos, calculated from the ratios of USW/ DSW for snow-free conditions, are listed in Table 4. Both the Terra and Aqua surface albedos exceed the surface observations. The differences are minimal during winter and greatest during autumn. Except for the uncertainties in the surface measurements noted earlier, the CERES USW biases are the result of errors in DSW and surface albedo. If the surface albedo is too large and DSW is too small, the errors tend to compensate each other resulting in smaller than expected biases in USW. Assuming that the regional surface albedo used by CERES is more representative of the entire area surrounding SACOL, it may be concluded that the biases over the area are actually due to underestimating DSW.

Xia et al. (2006) intercompared DSW from four datasets: China Meteorological Administration (CMA) 46 first-class sites, National Centers for Environment Prediction (NCEP) reanalysis data, and satellite estimates of ISCCP-FD data (Zhang et al., 2004) and University of Maryland (UMD) version of GEWEX SRB algorithm (Pinker \& Laszlo, 1992). They found that NCEP reanalysis solar radiation data overestimate surface observations by $40 \mathrm{~W} \mathrm{~m}^{-2}$ to more than $100 \mathrm{~W} \mathrm{~m}^{-2}$ over China, and the differences between satellite estimates and surface observations of annual mean solar insolation are about $-10 \mathrm{~W} \mathrm{~m}^{-2} \sim-25 \mathrm{~W} \mathrm{~m}^{-2}$ in the interior of China. Quan et al. (2009) validated net surface solar radiation in CERES/SSF satellite data, which is calculated using the Li model (Li et al., 1993) and the model of Masuda et al. (1995), over Shangdianzi, Beijing during January, April, July, and October in 2005, and their results show that the Li and Masuda models overestimate the net surface flux by $62.2 \mathrm{~W} \mathrm{~m}^{-2}$ and $50.8 \mathrm{~W} \mathrm{~m}^{-2}$, respectively, under clear skies and 82.1 and $71.8 \mathrm{~W} \mathrm{~m}^{-2}$ in cloudy skies. The results in Fig. 1 and Table 2 clearly show that the CERES surface DSW radiation flux is more accurate for the interior of China than the earlier model and satellite-based estimates. 

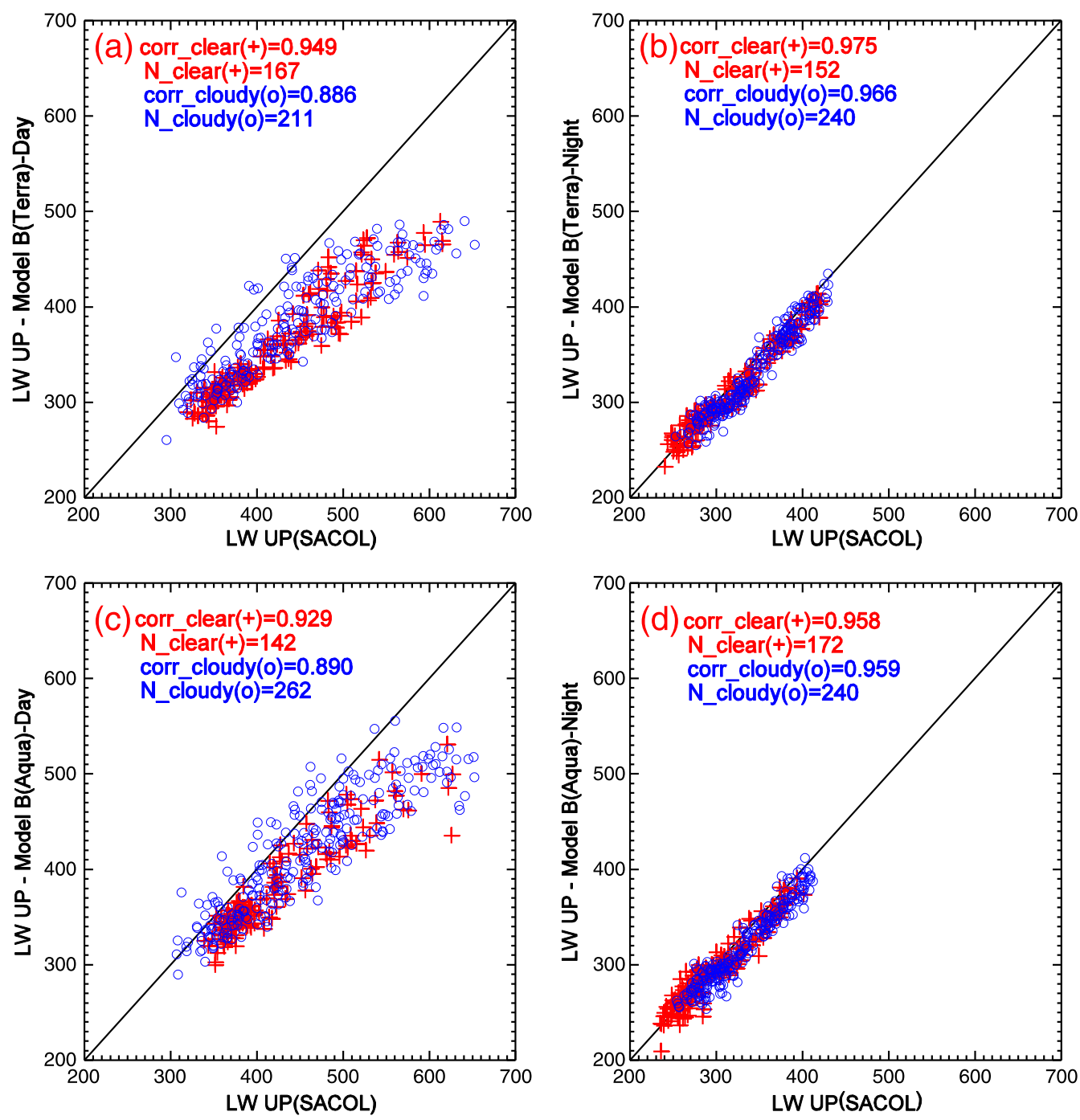

Fig. 5. Same as Fig. 3, except for surface upward longwave radiative flux.

\subsection{Surface longwave radiative flux}

Fig. 3 compares the day and night DLW calculated by the LPLA from Terra and Aqua data with the surface measurements. During the day, the clear-sky and cloudy daytime fluxes from Terra appear evenly distributed along the line of agreement (Fig. 3a), while those from Aqua exceed the surface values mostly at the low end (Fig. 3c). On average, the Terra and Aqua derived DLW fluxes differ from their surface counterparts by $-0.5 \mathrm{~W} \mathrm{~m}^{-2}$ and $1.8 \mathrm{~W} \mathrm{~m}^{-2}$ in clear-skies, respectively, and overestimate the surface radiative flux by $3.5 \mathrm{~W} \mathrm{~m}^{-2}$ and $7.0 \mathrm{~W} \mathrm{~m}^{-2}$ in cloudy conditions. Table 3 a shows that the absolute values of the clearsky biases are larger than those in cloudy conditions, expect during winter. Under clear conditions, the satellite-retrieved DLW is an underestimate during spring and summer, especially for Aqua, but is too large in winter. These biases suggest seasonally dependent errors in the temperature and humidity profiles used in the satellite algorithm and possibly the presence of aerosols not taken into account in the retrievals. The greater cloudy-sky bias during winter is probably due to a bias in the cloud base pressure. If the estimated base height of the cloud is lower than its true value, the cloud contribution to DLW will be overestimated based on Eqs. (4) and (5). Generally, the SD of the daytime differences is between 3.5 and 6.1\%. The mode of the differences for both cloudy and clear skies (Fig. $4 \mathrm{a}$ ) is close to $0 \%$, but the distribution is skewed to positive values, especially for cloudy skies.
Unlike the daytime results, the nocturnal satellite retrievals typically underestimate the surface DLW in both cloudy and cloud-free skies (Fig. $3 \mathrm{~b}$ and d). Like the daytime values, the nighttime differences are distributed in a nearly normal fashion, but the peak of the distributions is shifted to $-5 \%$ at night (Fig. $4 \mathrm{~b}$ ). The skew to the negative side is stronger for the clear scenes. Overall, the nighttime satellite-derived DLW is more inaccurate than during daytime as reflected by greater magnitude of the biases. Moreover, the biases are negative for all seasons. Without the MODIS visible channel at night, it is more difficult to detect low clouds. If low clouds were present for some of the scenes classified as clear, the satellite-derived DLW would be significantly underestimated. It is also possible that the model temperature and humidity profiles are less accurate during nighttime. Temperature profiles determined from Profiling Microwave Radiometer (TP/WVP3000) measurements show that a temperature inversion layer nearly always exists over SACOL at night (Huang et al., 2010). If this inversion layer is not properly represented in the sounding, either in position, strength, or existence, the DLW would likely be underestimated. For both Terra and Aqua, the fact that the SDs of the differences in cloudy conditions exceed those in clear-skies (Table 3a) confirms that the input cloud information, such as cloud fraction, cloud emissivity and cloud base height, brings some additional uncertainty to the retrievals.

Kratz et al. (2010) compared DLW derived from the CERES LPLA to surface measurements at various sites around the globe and found 

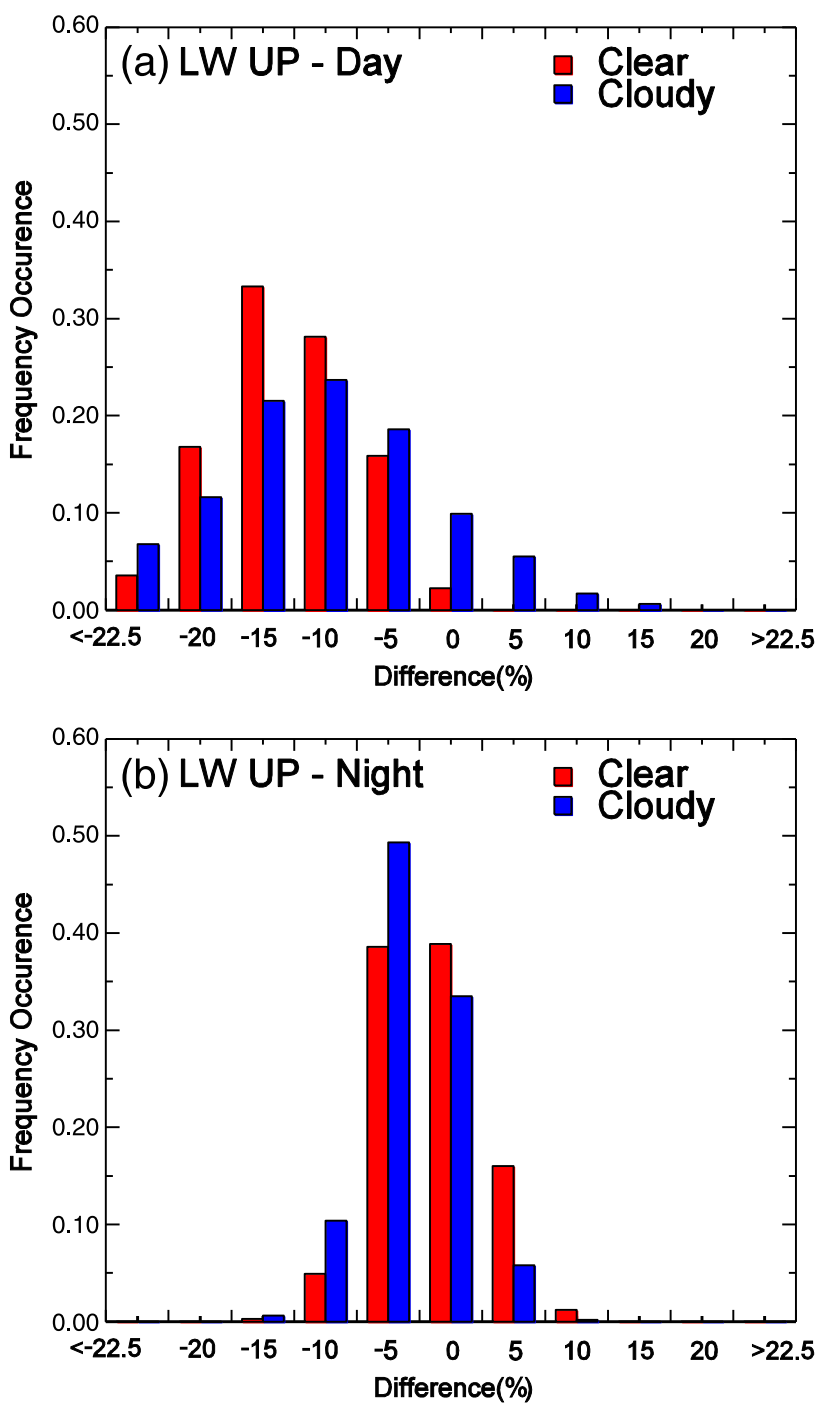

Fig. 6. Same as Fig. 2, except for the data presented in Fig. 5.

average biases of -7.2 and $-3.5 \mathrm{Wm}^{-2}$ for clear and cloudy skies, respectively, over North American and European continental sites. The biases found over SACOL are about $8 \mathrm{Wm}^{-2}$ greater, on average, than those over those other continental sites. While not reported specifically for continental sites, the DLW biases reported globally by Kratz et al. (2010) decreased by $\sim 9 \mathrm{Wm}^{-2}$ from day to night compared to $\sim 15 \mathrm{Wm}^{-2}$ over SACOL and $\sim 12 \mathrm{~W} \mathrm{~m}^{-2}$ over the Atmospheric Radiation Measurement (ARM) Southern Great Plains Central Facility (SCF) as reported by Gupta et al. (2004).

The corresponding comparisons of ULW from Terra and Aqua in Fig. 5 show that both the Terra and Aqua CERES-derived fluxes considerably underestimate the surface ULW fluxes, especially during daytime (Figs. 5 and 6). The SDs of the differences during daytime are notably greater than those during the night (Table $3 \mathrm{~b}$ ). The biases are negative for all seasons both day and night, except for the clear sky scenes observed by Aqua during winter. The magnitudes of the biases in spring and summer are much larger than those in autumn and winter corresponding to the greater surface skin temperatures occurring during the longer days with more insolation. For daytime, the scatter is small, especially at the high end of the bias range for both Terra and Aqua.

There are mainly two factors, surface skin temperature and surface emissivity $\left(\varepsilon_{s}\right)$, affecting the satellite-retrieved ULW. For land surfaces, $\varepsilon_{s}$ usually ranges from 0.82 to 0.99 with larger values for vegetated surfaces and smaller ones for deserts. SACOL is located in a typical semi-arid region and the surface is mainly covered by short grass which is usually less than 15 -cm tall and covers less than $80 \%$ of the surface in summer and autumn (Wang et al., 2010). During spring and winter, the underlay of SACOL is barren. If the error in $\varepsilon_{S}$ is 0.01 , the corresponding bias of ULW would be $2.5 \sim 5.0 \mathrm{~W} \mathrm{~m}^{-2}$. Due to the surface emissivity mainly depending on underlay and vegetation coverage changing with the seasons and soil moisture, the relative differences among the comparisons for the four seasons can be explained by surface emissivity to some extent. Some of it is due to the seasonal changes in surface temperatures. Because ULW depends on the fourth power of temperature, seasonal differences in ULW errors are greater than the skin temperature differences. While $\varepsilon_{s}$ could not be the only reason for this underestimation, given that the averaged differences are not the same order of magnitude during daytime and nighttime, the inputted surface skin temperature might be another reason.

In order to comprehensively assess this assumption, the LW-model B (LPLA) input and surface-derived surface skin temperatures are compared in Fig. 7. The LPLA inputted surface skin temperature is taken from the GMAO GEOS-5 products, and this variable is also archived in FLASHFlux SSF datasets. At SACOL, an IR-thermometer is directed towards the surface from a height of $8 \mathrm{~m}$. According to Kirchhoff's Law, the total incidence of longwave radiation into the IR-thermometer from the surface is,

$R_{b}=\alpha T_{i r t}^{4}=\varepsilon_{s} \sigma T_{s}^{4}+\left(1-\varepsilon_{s}\right) D L W$,

where $T_{i r t}$ is the incident longwave brightness temperature when the IRthermometer is directed toward the surface, DLW is the incoming longwave radiation flux measured by pyrgeometers (CG4, Kipp and Zonen), $\sigma$ is the Stefan-Boltzman constant and $\varepsilon_{s}$ the surface emissivity. Zuo et al. (2009) estimated the ground heat flux for SACOL with an empirical emissivity of 0.96 , while surface emissivity around SACOL in CERES SSF dataset is about 0.987 . Thus, in this study $\varepsilon_{S}$ of SACOL is empirically assumed to be 0.978 in spring, 0.984 in summer, 0.986 in autumn, and 0.974 in winter. Although the surface emissivity is an approximation, the surface-derived surface skin temperature $\left(T_{s}\right)$, calculated from the following expression:

$T_{s}=\left(\frac{\alpha T_{i r t}^{4}-\left(1-\varepsilon_{s}\right) D L W}{\varepsilon_{S} \alpha}\right)^{1 / 4}$

is relatively insensitive to $\varepsilon_{s}$. For example, assuming DLW $=200 \mathrm{Wm}^{-2}$ and a surface emissivity of 0.99 , the value of $T_{S}$ retrieved assuming $\varepsilon_{s}=0.97$ overestimates $T_{s}$ by only about $1.5 \mathrm{~K}$.

As expected, the MOA surface skin temperature is less than that calculated from surface measurements by about $-1 \mathrm{~K}$ for daytime Terra and $-5 K$ at night for both Terra and Aqua (Table 5). However, in daytime, larger biases in ULW correspond to smaller average differences of surface skin temperature, while smaller ULW biases correspond to greater skin temperature biases during nighttime. Obviously, the inaccuracy of surface skin temperature also an not completely explain why the satellite-retrievals are underestimated.

Minnis et al. (2004) compared the LPLA surface radiation budget with ground-based observations over the ARM SCF found that the sign of the bias in ULW switches from negative in the daytime to positive at night with an average change of $\sim 8 \mathrm{~W} \mathrm{~m}^{-2}$. In this paper, the bias is strongly negative in the daytime while less negative at night with an average change of $\sim 51 \mathrm{~W} \mathrm{~m}^{-2}$. Part of the difference in the magnitudes of the change is likely due to the use of geostationary satellite data in the older study. The geostationary data provide ULW for a complete diurnal cycle, while Terra and Aqua retrieve ULW within $1.5 \mathrm{~h}$ of local noon. At those hours, the ULW is near its maximum value for the day, while the 

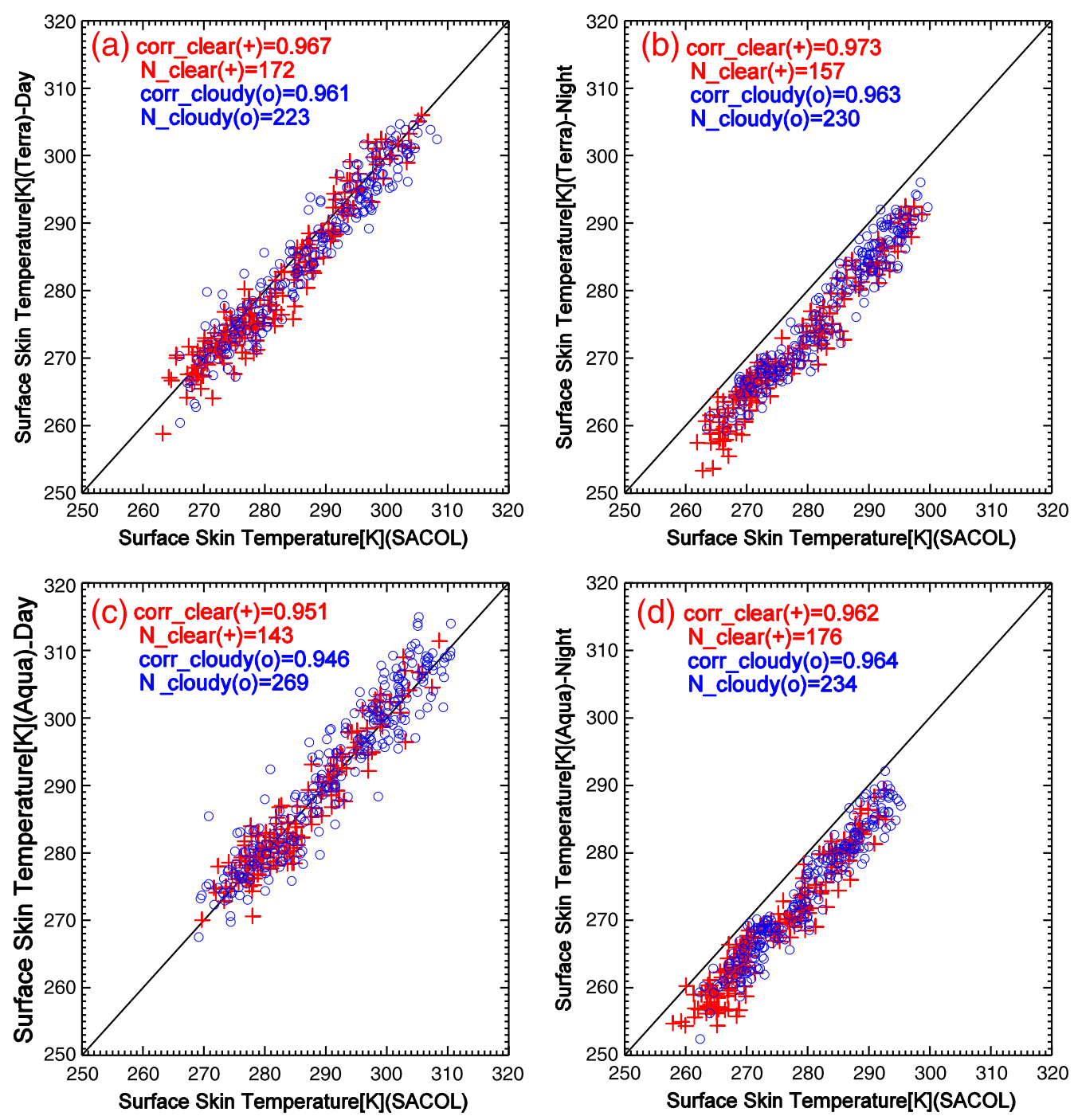

Fig. 7. Same as Fig. 3, except for surface skin temperature.

ARM study used mean values of measurements over all daytime hours. The nighttime ULW fluxes are much less variable over the course of the night especially after 2200 LT when the Terra and Aqua measurements are taken. Thus, a greater day-night bias change is expected when the extremes are used for the daytime values. Nevertheless, the divergence of the data from the line of agreement in Fig. $5 \mathrm{a}$ and $\mathrm{c}$ is explainable neither by the skin temperature and emissivity differences. In summary, the reasons for the underestimation of surface ULW from the satellites remain a mystery and require additional investigation.

\section{Conclusion}

On account of the important role of the CERES datasets in understanding climate change, it is essential to understand the uncertainties in the CERES parameters over all types of surfaces and geography. To better characterize the CERES surface flux uncertainties over the interior of eastern Asia, this paper presents an initial study comparing instantaneous surface radiation fluxes in the CERES SSF product with the same quantities measured directly at SACOL from July 2008 to March 2010. These fluxes were calculated using the NASA algorithms, LPSA and LPLA, with meteorological inputs from GEOS-5. Generally, most of the satellite-derived surface radiative budget components are highly correlated with the surface observations in all-sky conditions, despite some significant biases. For instance, the USW is overestimated by both Terra and Aqua in cloudy conditions; and ULW is heavily underestimated during daytime but slightly underestimated at night regardless of cloud coverage. The biases in the SW fluxes are comparable to those found over other continental sites, but the ULW biases are much larger than expected. Potential explanations for those biases reside in uncertainties in cloud parameters such as fractional coverage and base height, in surface scene type, and in surface albedo, temperature, and emissivity. The slight underestimation of DLW at night might be the result of improper characterization of inversions in the temperature and humidity profiles. Likewise, the CERES cloud mask has difficulty detecting very low clouds at night, a problem that will cause an underestimate of the DLW. Random errors for all-sky conditions were considerably larger than for clear-sky data because of the higher variability associated with clouds. The Aqua retrieval biases are all larger than their Terra counterparts. This offset between the two satellite biases could be the result of discrepancies in satellite instruments and calibrations (e.g., Minnis et al., 2008a). For satellite retrievals of surface radiative fluxes to be useful in climate research, acceptable accuracy requirements are about $\pm 20 \mathrm{~W} \mathrm{~m}^{-2}$ for instantaneous-footprint values and $\pm 10 \mathrm{~W} \mathrm{~m}^{-2}$ for monthly gridded products (Suttles \& Ohring, 1986). Thus, the satellite retrievals over the interior of China need additional analysis and more complete validation, including comparisons with cloud parameters, to improve their quality, especially for daytime ULW.

So far, the NASA LPSA and LPLA are important ways to estimate surface radiation budget and have undergone extensive validation both against ground-based flux measurements (Darnell et al., 1988, 
Table 5

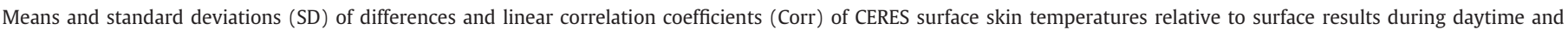
nighttime.

\begin{tabular}{|c|c|c|c|c|c|c|c|c|c|c|}
\hline & \multicolumn{10}{|c|}{$\mathrm{T}_{\mathrm{s}}(\mathrm{CERES})-\mathrm{T}_{\mathrm{s}}(\mathrm{sfc})$} \\
\hline & \multicolumn{5}{|l|}{ Day } & \multicolumn{5}{|c|}{ Night } \\
\hline & No. & $\begin{array}{l}\text { Bias } \\
(\mathrm{K})\end{array}$ & $\begin{array}{l}\text { SD } \\
(\mathrm{K})\end{array}$ & $\begin{array}{l}\text { SD } \\
(\%)\end{array}$ & corr & No. & $\begin{array}{l}\text { Bias } \\
(\mathrm{K})\end{array}$ & $\begin{array}{l}\text { SD } \\
(\mathrm{K})\end{array}$ & $\begin{array}{l}\text { SD } \\
(\%)\end{array}$ & corr \\
\hline Terra (clear) & 167 & -1.3 & 2.8 & 1.0 & 0.97 & 152 & -6.4 & 2.3 & 0.8 & 0.97 \\
\hline Terra (cloudy) & 211 & -1.4 & 3.0 & 1.1 & 0.96 & 240 & -6.0 & 2.5 & 0.9 & 0.96 \\
\hline Aqua (clear) & 142 & -0.1 & 2.9 & 1.0 & 0.95 & 172 & -5.9 & 2.5 & 0.9 & 0.96 \\
\hline Aqua (cloudy) & 262 & -0.8 & 3.8 & 1.3 & 0.95 & 240 & -5.7 & 2.3 & 0.8 & 0.96 \\
\hline
\end{tabular}

1992; Gupta et al., 1999, 2004; Kratz et al., 2010) and other more detailed radiative transfer model computations, such as line-by-line standards in the context of the Intercomparison of Radiation Codes in Climate Models (ICRCCM; Gupta et al., 1992, 1993; Ellingson et al., 1991). More validations are still needed for different surface types and locales, especially those in Asia, Africa, and South America. Furthermore, improvements in the accuracy of surface albedo maps, aerosol distributions, cloud radiative properties (e.g., Minnis et al., 2010), and meteorological inputs in the satellite processing will be included in future CERES processing. Those changes along with additional analyses using surface measurements, should make significant improvements in the satellite retrieval algorithms.

\section{Acknowledgments}

The CERES SSF data were obtained from the NASA Earth Observing System Data and Information System, Langley Research Center Atmospheric Sciences Data Center (ASDC). SACOL is sponsored by Lanzhou University through the 985 Program. The work is supported by National Science Foundation of China under Grants Nos. 40725015 and 40905007, the Fundamental Research Funds for the Central Universities LZUJBKY-2010-10, and the Ministry of Education, China through the Innovation Program to University. Support for Patrick Minnis was provided by the NASA CERES Project. We are grateful for the excellent support provided by the people at the College of Atmospheric Sciences, Lanzhou University.

\section{References}

Barkstrom, B. R. (1990). Earth radiation budget measurements: Pre-ERBE, ERBE, and CERES. Proceedings of SPIE, 1299, 52-60.

Caldwell, T. E., Coleman, L. H., Cooper, D. L., Escuadra, J., Fan, A., Franklin, C. B., et al. (2008). Clouds and the Earth's Radiant Energy System (CERES) data management system data products catalog. Release 4 Version 16, 240 pp., February. Available at. http://eosweb.larc.nasa.gov/PRODOCS/ceres/DPC/

Darnell, W. L., Staylor, W. F., Gupta, S. K., \& Denn, F. M. (1988). Estimation of surface insolation using sun-synchronous satellite data. Journal of Climate, 1, 820-835.

Darnell, W. L., Staylor, W. F., Gupta, S. K., Ritchey, N. A., \& Wilber, A. C. (1992). Seasonal variation of surface radiation budget derived from ISCCP-C1 data. Journal of Geophysical Research, 97, 15741-15760.

Ellingson, R. G., Ellis, J. S., \& Fels, S. B. (1991). The intercomparison of radiation codes used in climate models: Longwave results. Journal of Geophysical Research, 96, 8929-8953.

Fu, Q., Johanson, C. M., Wallace, J. M., \& Reichler, T. (2006). Enhanced mid-latitude tropospheric warming in satellite measurements. Science, 312, 1179.

Gupta, S. K. (1989). A parameterization for longwave surface radiation from sunsynchronous satellite data. Journal of Climate, 2, 305-320.

Gupta, S. K., Darnell, W. L., \& Wilber, A. C. (1992). A parameterization for longwave surface radiation from satellite data: Recent improvements. Journal of Applied Meteorology, 31, 1361-1367.

Gupta, S. K., Kratz, D. P., Stackhouse, P. W., Jr., \& Wilber, A. C. (2001). The Langley Parameterized Shortwave Algorithm (LPSA) for surface radiation budget studies version 1.0 (pp. 26). NASA/TP-2001-211272.

Gupta, S. K. Kratz, D. P., Wilber, A. C., \& Nguyen, L. C. (2004). Validation of parameterized algorithm used to derive TRMM-CERES surface radiative fluxes. Journal of Atmospheric and Oceanic Technology, 21, 742-751.

Gupta, S. K., Ritchey, N. A., Wilber, A. C., Whitlock, C. H., Gibson, G. G., \& Stackhouse, P. W., Jr (1999). A climatology of surface radiation budget derived from satellite data. Journal of Climate, 12, 2691-2710.
Gupta, S. K., Wilber, A. C., Darnell, W. L., \& Suttles, J. T. (1993). Longwave surface radiation over the globe from satellite data: An error analysis. International Journal of Remote Sensing, 14, 95-114.

Gupta, S. K., Wilber, A. C., Ritchey, N. A., Rose, F. G., Alberta, T. L., Charlock, T. P., et al. (1997). Regrid humidity and temperature fields (system 12.0). CERES algorithm theoretical basis document release 2.2, NASA/RP-1376. 20 pp. [Available online at]. http://asd-www.larc.nasa.gov/ATBD/ATBD.html

Hartmann, D. L., Ramanathan, V., Berroir, A., \& Hunt, G. E. (1986). Earth radiation budget data and climate research. Reviews of Geophysics, 24, 439-468.

Huang, J., He, M., Yan, H., Zhang, B., Bi, J., \& Jin, O. (2010). A study of liquid water path and precipitable water vapor in Lanzhou area using ground-based microwave radiometer. (in Chinese). Chinese Journal of Atmospheric Sciences, 34, 548-558.

Huang, J., Zhang, W., Zuo, J., Bi, J., Shi, J., Wang, X., et al. (2008). An overview of the semiarid climate and environment research observatory over the Loess Plateau. Advances in Atmospheric Sciences, 25, 1-16.

Inamdar, A. K., \& Ramanathan, V. (1997). On monitoring the water vapor feedback from space: Demonstration with CERES instrument. Tellus, 49B, 216-230.

Kopia, L. P. (1986). Earth radiation budget experiment scanner instrument. Reviews of Geophysics, 24, 400-406.

Kratz, D. P., Gupta, S. K., Wilber, A. C., \& Sothcott, V. E. (2010). Validation of the CERES edition 2B surface-only flux algorithm. Journal of Applied Meteorology and Climatology, 49, 164-180.

Li, Z., \& Garand, L. (1994). Estimation of surface albedo from space: A parameterization for global application. Journal of Geophysical Research, 99, 8335-8350.

Li, Z., Leighton, H. G., Masuda, K., \& Taksahima, T. (1993). Estimation of SW flux absorbed at the surface from TOA reflected flux. Journal of Climate, 6, 317-330.

Masuda, K., Leighton, H. G., \& Li, Z. Q. (1995). A new parameterization for the determination of solar flux absorbed at the surface from satellite measurements. Journal of Climate, 8, 1615-1628.

Minnis, P., Doelling, D. R., Nguyen, L., Miller, W. F., \& Chakrapani, V. (2008). Assessment of the visible channel calibrations of the TRMM VIRS and MODIS on Aqua and Terra. Journal of Atmospheric and Oceanic Technology, 25, 385-400.

Minnis, P., Kratz, D. P., Charlock, T. P., Doeling, D. R., Nordeen, M. L., Khaiyer, M. M., et al. (2004). Surface radiation budget from ARM satellite retrievals. Fourteenth ARM Science Team Meeting Proceeding, Albuquerque, New Mexico, March 22-26.

Minnis, P., Sun-Mack, S., Trepte, Q. Z., Chang, F. -L., Heck, P. W., Chen, Y., et al. (2010). CERES edition 3 cloud retrievals. AMS 13th Conf. Atmos. Rad., Portland, OR, June $27-$ July 2, 5.4.

Minnis, P., Trepte, Q. Z., Sun-Mack, S., Chen, Y., Doelling, D. R., Young, D. F., et al. (2008). Cloud detection in non-polar regions for CERES using TRMM VIRS and Terra and Aqua MODIS data. IEEE Transactions on Geoscience and Remote Sensing, 46, 3857-3884

Minnis, P., Sun-Mack, S., Young, D. F., Heck, P. W., Garber, D. P., Chen, Y., et al. (2011). CERES Edition-2 cloud property retrievals using TRMM VIRS and Terra and Aqua MODIS data, Part I: Algorithms. Submitted to IEEE Transactions Geoscience and Remote Sensing.

Ohmura, A., Dutton, E. G., Forgan, B., Frohlich, C., Gilgen, H., Hegner, H., et al. (1998). Baseline Surface Radiation Network (BSRN/WCRP): New precision radiometry for climate research. Bulletin of the American Meteorological Society, 79, $2115-2136$

Pinker, R. T., \& Laszlo, I. (1992). Modeling surface solar irradiance for satellite applications on a global scale. Journal of Applied Meteorology, 31(2), 194-211.

Quan, W., Chen, H., Guo, W., Xia, X., \& Zhang, X. (2009). Net surface solar radiation over Beijing area derived by two parameterization models: A comparison. (in Chinese). Acta Meteorologica Sinica, 67, 623-630.

Ramanathan, V. (1987). The role of Earth radiation budget studies in climate and general circulation research. Journal of Geophysical Research, 92, 4075-4095.

Ramanathan, V., Cess, R. D., Harrison, E. F., Minnis, P., Barkstrom, B. R., Ahmed, E., et al. (1989). Cloud-radiative forcing and climate: Results from the Earth radiation budget experiment. Science, 243, 57-63.

Stackhouse, P. W., Kratz, D. P., McGarragh, G. R., Gupta, S. K., \& Geier, E. B. (2006). Fast Longwave and Shortwave Radiative Flux (FLASHFlux) products from CERES and MODIS measurements. 12th Conference on Atmospheric Radiation, American Meteorological Society, Madison, Wisconsin, 10-14 July 2006

Staylor, W. F., \& Wilber, A. C. (1990). Global surface albedos estimated from ERBE data. Seventh Conference on Atmospheric Radiation, San Francisco, CA (pp. 231-236). : American Meteorological Society.

Suttles, J. T., \& Ohring, G. (1986). Surface radiation budget for climate applications. NASA Ref. Publ., 1169, 132 pp. 
Tian, W., Chen, C., Huang, J., \& Zhang, L. (1997). The solar heating effect of the winter aerosol in Lanzhou and its influence on evolution of the mixes layer. (in Chinese). Journal of Applied Meteorology, 8, 292-301.

Wang, G., Huang, J., Guo, W., Zuo, J., Wang, J., Bi, J., et al. (2010). Observation analysis of land-atmosphere interactions over the Loess Plateau of northwest China. Journal of Geophysical Research, 115, D00K17. doi:10.1029/2009JD013372

Wielicki, B. A., Barkstrom, B. R., Baum, B. A., Charlock, T. P., Green, R. N., Kratz, D. P., et al. (1998). Clouds and the Earth's Radiant Energy System (CERES): Algorithm overview. IEEE Transactions on Geoscience and Remote Sensing, 36, 1127-1141.

Wielicki, B. A., Barkstrom, B. R., Harrison, E. F., Lee, R. B., III, Smith, G. L., \& Cooper, J. E. (1996). Cloud and the Earth's Radiant Energy System (CERES): An Earth observing system experiment. Bulletin of the American Meteorological Society, 77, 853-868.

Wilber, A. C., Kratz, D. P., \& Gupta, S. K. (1999). Surface emissivity maps for use in satellite retrievals of longwave radiation. NASA TP 1999-209362 (pp. 35).
Xia, X., Wang, P., Chen, H., \& Liang, F. (2006). Analysis of downwelling surface solar radiation in China from National Centers for Environmental Prediction reanalysis, satellite estimates, and surface observations. Journal of Geophysical Research, 111 D09103. doi:10.1029/2005JD006405

Zhang, Y. C., Rossow, W. B., Lacis, A. A., Oinas, V., \& Mishchenko, M. I. (2004). Calculation of radiative fluxes from the surface to top of atmosphere based on ISCCP and other global datasets: Refinements of the radiative transfer model and the input data. Journal of Geophysical Research, 109, D19105. doi:10.1029/2003JD004457

Zuo, J., Huang, J., Wang, J., Zhang, W., Bi, J., Wang, G., et al. (2009). Surface turbulent flux measurements over the Loess Plateau for a semi-arid climate change study. Advances in Atmospheric Sciences, 26(4), 679-691. 